OPEN ACCESS

Edited by:

Martha J. Somerman, National Institutes of Health $(\mathrm{NIH})$,

United States

Reviewed by:

Olivier Huck,

Université de Strasbourg, France

Nurcan Buduneli,

Ege University, Turkey

*Correspondence:

Mauro P. Santamaria

mauro.santamaria@unesp.br

Specialty section: This article was submitted to Periodontics,

a section of the journal Frontiers in Dental Medicine

Received: 28 February 2021 Accepted: 07 April 2021

Published: 30 April 2021

Citation:

Osugue R, Castro dos Santos NC, Araujo CF, de Almeida FX, Feres $M$

and Santamaria MP (2021)

Periodontitis Is Associated With Risk of Conventional Stent Restenosis:

Pillot Case-Control Study.

Front. Dent. Med. 2:673626.

doi: 10.3389/fdmed.2021.673626

\section{Periodontitis Is Associated With Risk of Conventional Stent Restenosis: Pilot Case-Control Study}

\author{
Raphael Osugue ${ }^{1}$, Nidia C. Castro dos Santos ${ }^{1,2}$, Cassia F. Araujo ${ }^{1}$, Flavio X. de Almeida ${ }^{2}$ \\ Magda Feres ${ }^{2}$ and Mauro P. Santamaria ${ }^{1 *}$
}

${ }^{1}$ Division of Periodontics, Institute of Science and Technology, UNESP - São Paulo State University, São José dos Campos, Brazil, ${ }^{2}$ Dental Research Division, Guarulhos University, Guarulhos, Brazil

Objectives: Percutaneous coronary angioplasty with stent implantation has been established as the main form of treatment of atherosclerosis. However, 16 to $44 \%$ of patients may evolve with stent restenosis. Periodontitis is an inflammatory condition associated with bacterial infection, that may lead to periodontal tissue destruction and tooth loss. This study aimed to evaluate the association between stent restenosis and periodontitis.

Materials and Methods: Coronary angiography exams presenting stent imaging with and without restenosis were analyzed. Patients meeting the inclusion and exclusion criteria were selected and allocated in 2 groups: case (restenosis) and control (without restenosis). We evaluated if systemic and periodontal variables were predictors of restenosis (primary outcome) using a multivariable stepwise logistic regression. Additionally, we compared clinical and periodontal conditions between the control and case groups (secondary outcomes) using Chi-square test and ANOVA test.

Results: Data from 49 patients (case $n=15$; control $n=34$ ) were analyzed. The results showed that stages III and IV periodontitis and lack of physical activity were significant predictors of stent restenosis (OR 5.82 and 5.98, respectively). Comparisons regarding the diagnosis of periodontal conditions between control and case groups did not present significant differences in the incidence of periodontitis and alveolar bone loss.

Conclusion: Stages III and IV periodontitis increased the incidence of stent restenosis. These findings suggest that advanced stages of periodontal disease might lead to the occurrence of negative outcomes after coronary angioplasty with stent placement.

Keywords: atherosclerosis, cardiovascular disease, stent restenosis, periodontitis, inflammation

\section{INTRODUCTION}

Atherosclerosis is a progressive fibroproliferative chronic systemic inflammatory process that affects the intima layer of the middle and large vessels, culminating in the formation of atherosclerotic plaque. Its etiology is multifactorial with dyslipidemia, systemic arterial hypertension, diabetes, smoking, and the genetic hereditary component as the main risk factors for the development of atherosclerosis and coronary artery disease (CAD) (1). These factors increase the permeability of the intima to plasma lipoproteins in the subendothelial space, which when 
oxidized by macrophages become foam cells that are the main component of fatty striae. These immunogenic components stimulate the migration and proliferation of smooth muscle cells from the middle to the intimal layer to produce extracellular matrix that will form part of the fibrous cap of the atherosclerotic plaque $(2,3)$.

In the last three decades, interventional cardiology has established itself as the main form of myocardial revascularization in the treatment of coronary artery disease. Despite advances in procedural techniques and materials, about 16 to $44 \%$ of patients eventually evolve into an event called stent restenosis $(4,5)$. Restenosis is the onset of new obstruction $>50 \%$ in the segment previously treated with stent (6) and occurs between the second and sixth month $(7,8)$ up to the 8 months after implantation of a conventional stent (9). Clinically it may manifest with the return of signs and/or symptoms of myocardial ischemia, associated with angiographic confirmation of new obstruction of the stent. This is the most commonly used concept and is based on vascular physiology studies where from this degree of obstruction we can observe impairment of the coronary flow reserve $(10,11)$.

Periodontal diseases are inflammatory diseases associated with bacterial infection (12). The initial clinical presentation is gingivitis, which perpetuates the infectious-inflammatory process over the years. In susceptible individuals, gingivitis may be modified by multiple host response genes and, in combination with lifestyle and environmental factors, can culminate in the destructive form of periodontal disease, namely periodontitis (13). Periodontitis is considered a worldwide health problem (14) that over the years has demanded global health policies and programs that can assist in its prevention and treatment (15). It is a highly prevalent disease, with its moderate form affecting $50 \%$ and a severe form affecting 5 to $15 \%$ of the global adult population (16). Since it was suggested that periodontitis could decrease life expectancy (17), much has been researched on the influence of this disease on quality of life and systemic health of individuals, including cardiovascular disease $(18,19)$, pregnancy complications (20), neurological diseases $(21,22)$ and diabetes $(23,24)$.

Host-microbe interaction in the periodontium can initiate or even aggravate atherosclerotic processes through the activation of innate immunity, bacteremia, and direct involvement of cytokines and inflammatory proteins of oral microbiota (2527). The association between atherosclerosis and periodontal diseases has already been corroborated in both acute coronary disease and acute myocardial infarction (28, 29), indicating the presence of periodontal diseases as a factor of clinical decompensation of coronary atherosclerosis (30). Despite this, we do not know whether the chronic inflammatory process triggered by periodontal diseases can interfere with the longterm outcome of patients undergoing coronary angioplasty with a consequent episode of restenosis. Whether periodontal diseases, due to their chronic systemic inflammatory state, would be contributing to an increase in restenosis rates of conventional stents is not defined in the literature. Besides that, it is not routine in the clinical practice of interventional cardiologists to consider the oral health status before performing surgical coronary angioplasty. To date, there are no studies evaluating the possible relationship between conventional stent restenosis and periodontal diseases. Therefore, the aim of the present study is to evaluate the association between stent restenosis and periodontitis.

\section{MATERIALS AND METHODS Experimental Design}

This was an observational, retrospective, case-control, population-based study designed to evaluate the association between conventional stent restenosis and periodontal diseases. This study was approved by the human subjects ethics board of UNESP (CAAE: 60607916.9.0000.0077) and was conducted in accordance with the Helsinki Declaration of 1975, as revised in 2013 .

\section{Study Population and Inclusion and Exclusion Criteria}

Data from coronary angiography examinations performed at Pio XII Hospital (São José dos Campos, SP, Brazil) from January 4th, 2016 to February 28th, 2018 were analyzed. The study population consisted of patients who underwent coronary angiography at the referred hospital during the established period. Detailed medical records were obtained. Volunteers who fulfilled the inclusion criteria were invited to participate in the study. Inclusion criteria were prior coronary angioplasty with conventional stent implantation; aged $\geq 40$. Exclusion criteria were: edentulism; diabetes mellitus with glycated hemoglobin (HbA1c) levels $>7.0 \%$; pharmacological stent implantation; restenosis in stents implanted over the previous 2 years. Informed consent was provided by each volunteer after a thorough explanation of the nature, risks, and benefits of the clinical investigations.

\section{Allocation}

Patients were allocated into two groups according to the criteria below:

- Case Group: Patients who underwent coronary angiography examination of stent with restenosis, whose stent implantation occurred within 2 years.

- Control Group: Patients who presented coronary angiography with stent image without restenosis regardless of the implantation period.

\section{Cardiovascular Evaluation}

For the screening and selection of candidates for both study groups, the reports previously made by interventional cardiologists at the Pio XII Hospital were used. For the definition of angiographic restenosis in coronary angiography reports, the Interventional Cardiology societies criteria were used. These criteria are based on studies of vascular physiology, in which the impairment of coronary flow reserve can be observed considering the degree of obstruction, and consists of the presence of $>70 \%$ from the lesion in the stent-treated segment (within the stent and within $5 \mathrm{~mm}$ beyond the stent) (4). Restenosis was classified using the Guideline Reference 
for Percutaneous Coronary Intervention by the American Heart Association $(31,32)$. This classification is based on the geographic distribution of intimal hyperplasia in reference to the implanted stent. Peripheral blood was collected to evaluate
HbA1c levels and lipid profile. Anthropometric measures including weight and height were recorded. Body mass index (BMI) was calculated as the weight divided by the square of height $\left(\mathrm{kg} / \mathrm{m}^{2}\right)$.

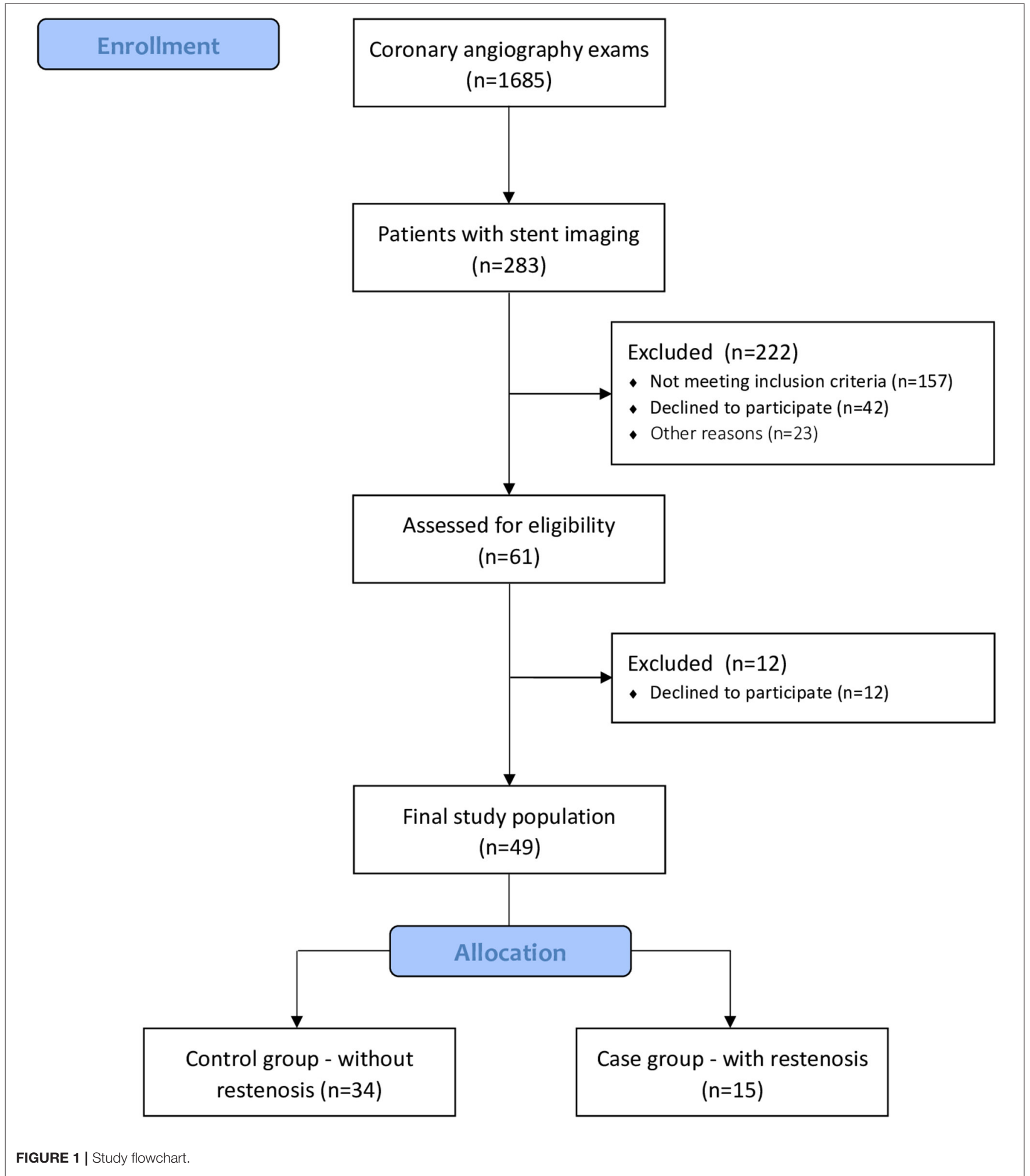




\section{Periodontal Evaluation}

All patients were scheduled for a periodontal evaluation at the Department of Periodontology at the Institute of Science and Technology, São Paulo State University-Unesp (São José dos Campos, SP, Brazil). In this session, a throughout periodontal examination was performed by two trained and calibrated periodontists (CFA and NCCS). The examiners participated in a calibration exercise in which PD and CAL of 10 patients were measured twice within a 24-h interval. These measurements were subjected to an intraclass correction test. The agreement for the variables was $>90 \%$.

The evaluated parameters were: (1) Probing depth (PD); (2) Clinical attachment level (CAL); (3) Gingival recession (GR); (4) Bleeding on probing (BoP); (5) Supragingival biofilm accumulation (Pl) (33). All clinical measures were assessed using a manual probe (University of North Carolina Probe PCPUNCBR 15, Hu-Friedy).

The presence or absence of periodontal diseases, the diagnosis, and classification of the diseases, the quantification of the extent and severity of the diseases, and the estimated duration of the diseases were determined $(34,35)$.

\section{Alveolar Bone Loss Analysis}

Panoramic radiographs were obtained by a radiologist and evaluated by a trained examiner. The examiner was blind to the status of each group of participants. The severity of alveolar bone loss was measured as a percentage of bone loss in the interproximal sites of each tooth (36). Each site was assigned a score from 1 through 4 according to alveolar bone (1: 0 to $24 \%$; 25 to $49 \%$; $3: 50$ to $74 \%$; 4 : 75 to $100 \%)$. We defined a mean bone loss score $\leq 2$ as mild to moderate periodontal bone loss and score $>2$ as severe alveolar bone loss.

\section{Statistical Analysis}

Data were recorded as mean and standard deviation, median with quartiles or percentage according to the different variables analyzed. Normal distribution was tested by Shapiro-Wilk. For the comparison of quantitative variables, the mean and standard deviation were used. For percentages, Chi-square test $\left(\chi^{2}\right)$ was used for qualitative variables. ANOVA test was used to compare groups for mean age and BMI. A multivariable stepwise logistic regression was performed to verify if there is a relationship between restenosis (dependent variable) and independent variables. All data analyses were performed using IBM SPSS, Minitab, and Excel Office. A significance level of 0.05 (5\%) was defined for this study, and all confidence intervals throughout the study were constructed with $95 \%$ statistical confidence.

\section{RESULTS}

A total of 1,685 coronary angiography examinations performed during the period from January 4th, 2016 to February 28th, 2018 were analyzed. At the end of volunteer selection, 61 patients were eligible. Of these, 49 patients accepted to participate in the study and underwent periodontal evaluation (Figure 1). Table 1 presents sociodemographic characteristics of the control group
TABLE 1 | Socioeconomic and clinical characteristics for control and case groups.

\begin{tabular}{lccc}
\hline Variables & $\begin{array}{c}\text { Control group } \\
(\boldsymbol{n}=\mathbf{3 4})\end{array}$ & $\begin{array}{c}\text { Case group } \\
(\boldsymbol{n}=\mathbf{1 5})\end{array}$ & P-value \\
\hline Gender (male) & $24(70 \%)^{\mathrm{A}}$ & $13(86 \%)^{\mathrm{A}}$ & 0.228 \\
Age (years) & $60.60 \pm 8.00^{\mathrm{A}}$ & $59.10 \pm 8.50^{\mathrm{A}}$ & 0.542 \\
BMl (kg/m $)$ & $27.91 \pm 3.50^{\mathrm{A}}$ & $27.12 \pm 3.466^{\mathrm{A}}$ & 0.495 \\
Arterial hypertension & $31(96 \%)^{\mathrm{A}}$ & $12(85 \%)^{\mathrm{A}}$ & 0.158 \\
Diabetes mellitus & $8(23 \%)^{\mathrm{A}}$ & $5(33 \%)^{\mathrm{A}}$ & 0.474 \\
Dyslipidemia & $27(84 \%)^{\mathrm{A}}$ & $12(86 \%)^{\mathrm{A}}$ & 0.907 \\
CAD & $16(50 \%)^{\mathrm{A}}$ & $9(64 \%)^{\mathrm{A}}$ & 0.371 \\
Smoker & $7(22 \%)^{\mathrm{A}}$ & $2(14 \%)^{\mathrm{A}}$ & 0.550 \\
Former smoker & $9(28 \%)^{\mathrm{A}}$ & $9(64 \%)^{\mathrm{B}}$ & 0.021 \\
Obesity & $9(28 \%)^{\mathrm{A}}$ & $3(21 \%)^{\mathrm{A}}$ & 0.634 \\
Brushing & $30(96 \%)^{\mathrm{A}}$ & $14(100 \%)^{\mathrm{A}}$ & 0.497 \\
\hline
\end{tabular}

$B M I$, body mass index; $C A D$, coronary artery disease.

Different uppercase indicates statistically significant differences between groups. Age and BMI were compared using one-way ANOVA. Intergroup percentages were compared using Chi-square test $\left(\chi^{2}\right)$.

TABLE 2 | Stepwise logistic regression considering restenosis as an outcome variable for all volunteers $(n=49)$.

\begin{tabular}{lll}
\multicolumn{3}{c}{ Restenosis } \\
\hline OR & $95 \%$ C.I. & $P$-value
\end{tabular}

Periodontitis

No

Stages III and IV 1.0

Physical activity

Yes

0.018

No

1.0

5.98

1.07-33.62

0.042

Covariables included are periodontitis, diabetes, obesity, smoking, physical activity, age, gender, number of teeth, and alveolar bone loss.

Nagelkerke $R^{2}=0.248$.

$(n=34)$ and the case group $(n=15)$. There was no statistical difference between most of the variables analyzed, except for previous smoking history (Table 1).

A binary logistic regression was performed to determine if demographic, systemic, and periodontal variables were predictors of restenosis. "Stages III and IV periodontitis" and "No regular physical activity" were significant predictors when restenosis was a dependent outcome variable (OR 5.82 and 5.98 , respectively). Other stages of periodontitis, controlled diabetes, obesity, current smoking, age, gender, number of teeth, and severe alveolar bone loss were not statistically significant (Table 2).

We evaluated the groups according to the frequency of different diagnoses and classifications of periodontal diseases. There was a higher percentage of gingivitis and Stages I and II periodontitis when the control group was compared to the case group. On the other hand, Stages III and IV periodontitis presented higher percentages in the case group than 
TABLE 3 | Incidence of periodontal diseases for the control and case groups.

\begin{tabular}{lcccccc}
\hline Variables & \multicolumn{2}{c}{ Control group } & & \multicolumn{2}{c}{ Case group } & \multirow{2}{*}{$\boldsymbol{P}$-value } \\
\cline { 2 - 3 } & $\boldsymbol{n}$ & $\%$ & & $\boldsymbol{n}$ & $\%$ & \\
\hline Gingivitis & 8 & 23.5 & & 2 & 13.3 & 0.414 \\
Stage I periodontitis & 5 & 14.7 & & 1 & 6.7 & 0.466 \\
Stage II periodontitis & 10 & 29.5 & & 3 & 20.0 & 0.492 \\
Stage III periodontitis & 5 & 14.7 & & 5 & 33.3 & 0.111 \\
Stage IV periodontitis & 6 & 17.6 & & 4 & 26.7 & 0.470 \\
\hline
\end{tabular}

Chi-square test $\left(\mathrm{x}^{2}\right)$ was used to compare the frequency of periodontal diseases between groups $(p<0.05)$.

in the control group. Despite these differences, no statistical significance was observed ( $p>0.05$ ) (Table 3).

For the comparison of alveolar bone loss scores between groups, the case group presented $4(36 \%)$ patients with alveolar bone loss score $\leq 2$, while 7 (63\%) patients presented score $>2$. In the control group, we observed that $11(38 \%)$ patients presented score $\leq 2$, and $18(62 \%)$ patients presented score $>2$. No statistical significance was observed in the intergroup comparison.

\section{DISCUSSION}

Stages III and IV periodontitis increased the risk of chances for stent restenosis. These results suggest that periodontitis is an important factor to be considered in the clinical cardiological evaluation routine before and after coronary angioplasty interventions.

Growing evidence suggests a link between periodontitis and cardiovascular disease, especially regarding the risk factors shared between these conditions. In this study population, all patients presented atherosclerosis and had already received conventional stent implantation treatment. Thus, the high prevalence of periodontal disease found in our study population is justified, confirming the same results found in a previous study (37). Besides having common risk factors, a mechanism linking the two diseases has been elucidated in a recent longitudinal study. Van Dyke et al. (38) evaluated the F-fluorodeoxyglucose positron emission tomography/computed tomography of 304 individuals, quantifying periodontal and arterial inflammation. The authors showed that periodontitis is associated with arterial inflammation and that periodontitis predicted subsequent major adverse cardiovascular events (38). These findings corroborate the main results of our study, which underscore the hypothesis that periodontitis could influence the occurrence and treatment of CAD.

In addition to periodontitis, we observed that physical activity was associated with a lower restenosis rate. It is well-documented that physical activity helps to control many cardiovascular risk factors (39). In patients with stable CAD, the measurement of Creactive protein (CRP) may be useful as an independent marker to assess the likelihood of recurrent events, including death, myocardial infarction, or stent restenosis (40), and physical activity in this type of patient is a factor that in itself reduces inflammatory markers such as CRP (41). Thus, the regular practice of physical activity could contribute as a protective factor for restenosis by reducing inflammation.

Risk factors associated with the development of periodontitis comprise local, systemic, and genetic factors, including smoking, diabetes, and possibly obesity (42). Contributions for cardiovascular disease are also multifactorial, which encompass ethnicity, age, family history of CAD, dyslipidemia, hypertension, smoking, obesity, and diabetes. Hence, there are many potentially important confounders for the association between periodontitis and atherosclerotic disease (19). The presence of confounding factors is a relevant limitation aspect of several observational studies (43). In the present study, we assessed if there was an association between risk factors shared by the two diseases and restenosis, but no significant results were observed.

Although diabetes mellitus is considered a risk factor that increases the likelihood of restenosis, patients with controlled diabetes $(\mathrm{HbAlc}<7.0 \%)$ do not present high restenosis rates after conventional stent implantation $(44,45)$. For this reason, patients with controlled diabetes were included in this study. As expected, controlled diabetes was not associated with an increased risk for restenosis in this study. One of the exclusion criteria was the presence of pharmacological stents, for the use of pharmacological stents alters the physiology of the stent endothelialization phenomenon by inhibiting the cell cycle in different stages, thus delaying the stent phenomenon of cell migration and proliferation (46). Despite the benefits of pharmacological stents observed in large randomized controlled clinical trials, the use of drug-eluting stenting implies longer dual anti-aggregation therapy, thereby increasing the risk of bleeding (47) and decreasing the cost-effectiveness of the procedure (48).

The findings of this study demonstrate that periodontitis is an important predictor of stent restenosis. Nevertheless, this result should be interpreted with caution. The main limitation of this study is the small sample size. Of the 1,685 coronary angiography examinations, 1,402 patients did not present stent imaging, which resulted in 283 possible volunteers for the study. Then, volunteer selection was particularly difficult for the exclusion criterion "edentulism," which was highly prevalent in the analyzed population. Possibly, most individuals presenting edentulism had lost their teeth due to periodontitis previously to this study. Thus, the number of observed events (restenosis) was modest (15 patients). The main strength of the present study is that periodontal diseases were evaluated as possible predictors for stent restenosis for the first time. This hypothesis was mechanistically plausible and demonstrated to be clinically relevant in this population. Additionally, evaluating the association between periodontal diseases and negative outcomes after cardiological interventions help to increase the awareness of the relevance of periodontal evaluation and treatment in patients with atherosclerosis.

Stages III and IV periodontitis is associated with the incidence of stent restenosis. These findings suggest that advanced stages of periodontal disease might lead to the occurrence of negative outcomes after coronary angioplasty with stent placement. 


\section{DATA AVAILABILITY STATEMENT}

The raw data supporting the conclusions of this article will be made available by the authors, without undue reservation.

\section{ETHICS STATEMENT}

The studies involving human participants were reviewed and approved by Human subjects ethics board-UNESP. The patients/participants provided their written informed consent to participate in this study.

\section{REFERENCES}

1. Yahagi K, Kolodgie FD, Otsuka F, Finn A V, Davis HR, Joner M, et al. Pathophysiology of native coronary, vein graft, and in-stent atherosclerosis. Nat Rev Cardiol. (2016) 13:79-98. doi: 10.1038/nrcardio.2015.164

2. Ross R, Glomset JA. The pathogenesis of atherosclerosis (first of two parts). $N$ Engl J Med. (1976) 295:369-77. doi: 10.1056/NEJM197608122950707

3. Otsuka F, Kramer MC, Woudstra P, Yahagi K, Ladich E, Finn A V, et al. Natural progression of atherosclerosis from pathologic intimal thickening to late fibroatheroma in human coronary arteries: a pathology study. Atherosclerosis. (2015) 241:772-82. doi: 10.1016/j.atherosclerosis.2015.05.011

4. Weintraub WS, Ghazzal ZM, Douglas JS, Liberman HA, Morris DC, Cohen CL, et al. Long-term clinical follow-up in patients with angiographic restudy after successful angioplasty. Circulation. (1993) 87:831-40. doi: 10.1161/01.CIR.87.3.831

5. Gershlick A, Brack MJ, More RS, Syndercombe-Court D, Balcon R. Angiographic restenosis after angioplasty: comparison of definitions and correlation with clinical outcome. Coron Artery Dis. (1993) 4: 73-81.

6. Roubin GS, King SB, Douglas JS. Restenosis after percutaneous transluminal coronary angioplasty: the Emory University Hospital experience. Am J Cardiol. (1987) 60:39B-43B. doi: 10.1016/0002-9149(87) 90482-6

7. Serruys PW, Luijten HE, Beatt KJ, Geuskens R, de Feyter PJ, van den Brand $\mathrm{M}$, et al. Incidence of restenosis after successful coronary angioplasty: a time-related phenomenon. A quantitative angiographic study in 342 consecutive patients at 1,2, 3, and 4 months. Circulation. (1988) 77:36171. doi: 10.1161/01.CIR.77.2.361

8. Nobuyoshi M, Kimura T, Nosaka H, Mioka S, Ueno K, Yokoi H, et al. Restenosis after successful percutaneous transluminal coronary angioplasty: serial angiographic follow-up of 229 patients. J Am Coll Cardiol. (1988) 12:616-23. doi: 10.1016/S0735-1097(88)80046-9

9. Gruentzig AR, King SB, Schlumpf M, Siegenthaler W. Long-term follow-up after percutaneous transluminal coronary angioplasty. The early Zurich experience. N Engl J Med. (1987) 316:112732. doi: 10.1056/NEJM198704303161805

10. Holmes DR, Schwartz RS, Webster MW. Coronary restenosis: what have we learned from angiography? J Am Coll Cardiol. (1991) 17(6 Suppl B):14B-22B. doi: 10.1016/0735-1097(91)90934-2

11. Kuntz RE, Baim DS. Defining coronary restenosis. Newer clinical and angiographic paradigms. Circulation. (1993) 88:131023. doi: 10.1161/01.CIR.88.3.1310

12. Page RC, Kornman KS. The pathogenesis of human periodontitis: an introduction. Periodontol. (1997) 14:911. doi: 10.1111/j.1600-0757.1997.tb00189.x

13. Bartold PM, Van Dyke TE. Periodontitis : a host-mediated disruption of microbial homeostasis. Unlearning learned concepts. Periodontology. (2013) 62:203-17. doi: 10.1111/j.1600-0757.2012.00450.x

14. Armitage GC, Research S ienc. TC of the AA of P. Diagnosis of periodontal diseases. J Periodontol. (2003) 74:1237-47. doi: 10.1902/jop.2003.74. 8.1237

\section{AUTHOR CONTRIBUTIONS}

RO: conception and design, selection of volunteers, and interpretation of data. NC: data acquisition, analysis, interpretation of data, and drafting article. CA: data acquisition and interpretation of data. FA: interpretation of data. MF: interpretation of data and drafting article. MS: conception and design, direction and implementation, interpretation, and drafting article. All authors contributed to the article and approved the submitted version.

15. Petersen PE, Ogawa $H$. Strengthening the prevention of periodontal disease: the WHO approach. J Periodontol. (2005) 76:2187-93. doi: 10.1902/jop.2005.76.12.2187

16. Holtfreter B, Albandar JM, Dietrich T, Dye BA, Eaton KA, Eke PI, et al. Standards for reporting chronic periodontitis prevalence and severity in epidemiologic studies: proposed standards from the Joint EU/USA Periodontal Epidemiology Working Group. J Clin Periodontol. (2015) 42:40712. doi: $10.1111 /$ jcpe. 12392

17. Buset SL, Walter C, Friedmann A, Weiger R, Borgnakke WS, Zitzmann NU. Are periodontal diseases really silent? A systematic review of their effect on quality of life. J Clin Periodontol. (2016) 43:333-44. doi: 10.1111/jcpe.12517

18. Dietrich T. Age-dependent associations between chronic periodontitis/ edentulism and risk of coronary heart disease. Bone. (2008) 23:1-7. doi: 10.1161/CIRCULATIONAHA.107.711507

19. Tonetti MS, Van Dyke TE. Periodontitis and atherosclerotic cardiovascular disease: consensus report of the Joint EFP/AAP Workshop on Periodontitis and Systemic Diseases. J Clin Periodontol. (2013) 40(Suppl. 14):249. doi: 10.1111/jcpe.12089

20. Armitage GC. Bi-directional relationship between pregnancy and periodontal disease. Periodontol. (2013) 61:160-76. doi: 10.1111/j.1600-0757.2011.00396.x

21. Hellvard A, Ryder MI, Hasturk H, Walker GD, Benedyk M, Lee A, et al. Porphyromonas gingivalis in Alzheimer's disease brains: evidence for disease causation and treatment with small-molecule inhibitors. Sci Adv. (2019) 5:eaau3333. doi: 10.1126/sciadv.aau3333

22. Gil-Montoya JA, Sanchez-Lara I, Carnero-Pardo C, Fornieles F, Montes J, Vilchez $\mathrm{R}$, et al. is periodontitis a risk factor for cognitive impairment and dementia? A case-control study. J Periodontol. (2015) 86:24453. doi: 10.1902/jop.2014.140340

23. Taylor GW. Bidirectional interrelationships between diabetes and periodontal diseases: an epidemiologic perspective. Ann Periodontol. (2001) 6:99112. doi: 10.1902/annals.2001.6.1.99

24. Casanova L, Hughes FJ, Preshaw PM. Diabetes and periodontal disease: a twoway relationship. Br Dent J. (2014) 217:433-7. doi: 10.1038/sj.bdj.2014.907

25. Schenkein HA, Loos BG. Inflammatory mechanisms linking periodontal diseases to cardiovascular diseases. J Clin Periodontol. (2013) 40(Suppl. 14). doi: $10.1111 /$ jcpe. 12060

26. Flores MF, Montenegro MM, Furtado M V, Polanczyk CA, Rosing CK, Haas AN. Periodontal status affects C-reactive protein and lipids in patients with stable heart disease from a tertiary care cardiovascular clinic. J Periodontol. (2014) 85:545-53. doi: 10.1902/jop.2013.130255

27. Reyes L, Herrera D, Kozarov E, Roldan S, Progulske-Fox A. Periodontal bacterial invasion and infection: contribution to atherosclerotic pathology. J Clin Periodontol. (2013) 40:S30-50. doi: 10.1111/jcpe. 12079

28. Widén C, Holmer H, Coleman M, Tudor M, Ohlsson O, Sättlin S, et al. Systemic inflammatory impact of periodontitis on acute coronary syndrome. J Clin Periodontol. (2016) 9:713-9. doi: 10.1111/jcpe.12540

29. Sidhu RK. Association between acute myocardial infarction and periodontitis: a review of the literature. J Int Acad Periodontol. (2016) 18:23-33.

30. Vedin O, Hagstrom E, Gallup D, Neely ML, Stewart R, Koenig W, et al. Periodontal disease in patients with chronic coronary heart disease: 
prevalence and association with cardiovascular risk factors. Eur J Prev Cardiol. (2015) 22:771-8. doi: 10.1177/2047487314530660

31. Mehran R, Dangas G, Abizaid AS, Mintz GS, Lansky AJ, Satler LF, et al. Angiographic patterns of in-stent restenosis: classification and implications for long-term outcome. Circulation. (1999) 100:1872-8. doi: 10.1161/01.CIR.100.18.1872

32. Levine GN, Bates ER, Blankenship JC, Bailey SR, Bittl JA, Cercek B, et al. 2011 ACCF/AHA/SCAI Guideline for Percutaneous Coronary Intervention: a report of the American College of Cardiology Foundation/American Heart Association task force on practice guidelines and the society for cardiovascular angiography and interventions. Circulation. (2011). 124:e574651. doi: 10.1161/CIR.0b013e31823a5596

33. Ainamo J, Bay I. Problems and proposals for recording gingivitis and plaque. Int Dent J. (1975) 25:229-35.

34. Caton J, Armitage G, Berglundh T, Chapple ILC, Jepsen S, Kornman K, et al. A new classification scheme for periodontal and peri-implant diseases and conditions - Introduction and key changes from the 1999 classification. J Clin Periodontol. (2018) 45:S1-8. doi: 10.1111/jcpe.12935

35. Papapanou PN, Sanz M, Buduneli N, Dietrich T, Feres M, Fine DH, et al. Periodontitis: consensus report of workgroup 2 of the 2017 World Workshop on the classification of periodontal and peri-implant diseases and conditions. J Clin Periodontol. (2018) 45:S162-70. doi: 10.1111/jcpe.12946

36. Schei O, Waerhaug J, Lovdal A, Arno A. Alveolar bone loss as related to oral hygiene and age. J periodontol. (1959) 30:7-16. doi: 10.1902/jop.1959.30.1.7

37. Accarini R, Godoy MF. Periodontal disease as a potential risk factor for acute coronary syndromes. Arq Bras Cardiol. (2007) 88:539-43. doi: 10.1590/s0066-782x2006001800007

38. Van Dyke TE, Kholy $\mathrm{K}$ El, Ishai A, Takx RAP, Mezue K, Abohashem SM, et al. Inflammation of the periodontium associates with risk of future cardiovascular events. J Periodontol. (2021) 92:348-58. doi: 10.1002/JPER.19-0441

39. Milani R V., Lavie CJ, Mehra MR. Reduction in C-reactive protein through cardiac rehabilitation and exercise training. J Am Coll Cardiol. (2004) 43:1056-61. doi: 10.1016/j.jacc.2003.10.041

40. Pearson TA, Mensah GA, Alexander RW, Anderson JL, Cannon RO, Criqui $\mathrm{M}$, et al. Markers of inflammation and cardiovascular disease: application to clinical and public health practice: a statement for healthcare professionals from the centers for disease control and prevention and the American Heart Association. Circulation. (2003) 107:499-511. doi: 10.1161/01.CIR.0000052939.59093.45

41. Rahimi K, Secknus MA, Adam M, Hayerizadeh BF, Fiedler M, Thiery J, et al. Correlation of exercise capacity with high-sensitive C-reactive protein in patients with stable coronary artery disease. Am Heart J. (2005) 150:12829. doi: 10.1016/j.ahj.2005.01.006

42. Borrell LN, Papapanou PN. Analytical epidemiology of periodontitis. J Clin Periodontol. (2005) 32(Suppl. 6):13258. doi: 10.1111/j.1600-051X.2005.00799.x

43. Hyman J. The importance of assessing confounding and effect modification in research involving periodontal disease and systemic diseases. J Clin Periodontol. (2006) 33:102-3. doi: 10.1111/j.1600-051X.2005.00881.x

44. Corpus RA, George PB, House JA, Dixon SR, Ajluni SC, Devlin WH, et al. Optimal glycemic control is associated with a lower rate of target vessel revascularization in treated type II diabetic patients undergoing elective percutaneous coronary intervention. J Am Coll Cardiol. (2004) 43:814. doi: 10.1016/j.jacc.2003.06.019

45. Kassaian SE, Goodarzynejad H, Boroumand MA, Salarifar M, Masoudkabir F, Mohajeri-Tehrani MR, et al. Glycosylated hemoglobin (HbAlc) levels and clinical outcomes in diabetic patients following coronary artery stenting. Cardiovasc Diabetol. (2012) 11:82. doi: 10.1186/1475-284 0-11-82

46. Morice M-C, Serruys PW, Souza JE. A randomized comparison of a Sirolimus-eluting stent with a standard stent for coronary revascularization. $N$ Engl J Med. (2002) 346:1773-80. doi: 10.1056/NEJMoa 012843

47. Yeh RW, Normand SLT, Wolf RE, Jones PG, Ho KKL, Cohen DJ, et al. Predicting the restenosis benefit of drug-eluting versus bare metal stents in percutaneous coronary intervention. Circulation. (2011) 124:155764. doi: 10.1161/CIRCULATIONAHA.111.045229

48. Amin AP, Spertus JA, Cohen DJ, Chhatriwalla A, Kennedy KF, Vilain $\mathrm{K}$, et al. Use of drug-eluting stents as a function of predicted benefit. Arch Intern Med. (2012) 172:1145-52. doi: 10.1001/archinternmed.201 2.3093

Conflict of Interest: The authors declare that the research was conducted in the absence of any commercial or financial relationships that could be construed as a potential conflict of interest.

Copyright (c) 2021 Osugue, Castro dos Santos, Araujo, de Almeida, Feres and Santamaria. This is an open-access article distributed under the terms of the Creative Commons Attribution License (CC BY). The use, distribution or reproduction in other forums is permitted, provided the original author(s) and the copyright owner(s) are credited and that the original publication in this journal is cited, in accordance with accepted academic practice. No use, distribution or reproduction is permitted which does not comply with these terms. 